\title{
ALTERNATE APPROACHES TO INTELLECTUAL DISABILITY
}

\author{
Kasinadar Kanesalingavelan'1, Sivam Sabhesan², Nallarangaramanujam Nammalvar³, Savitha Kanagaraj4 \\ ${ }^{1}$ Associate Professor, Department of Psychiatry, Sree Mookambika Medical College, Kulasekharam. \\ 2Professor (Rtd.), Department of Psychiatry, Madurai Medical College, Madurai. \\ ${ }^{3}$ Clinical Psychologist. \\ ${ }^{4}$ MBBS Intern.
}

\section{ABSTRACT}

Substantial number of parents owing to ignorance, illiteracy and lack of proper and effective treatments used to take their children for various interventions such as magico-religious treatments, alternative medicines and unproved treatment modalities.

\section{AIM}

The aim was to study the resource utilisation of the families of intellectual disability by taking a longitudinal history of various attempts to care children by the caregivers.

\section{MATERIALS AND METHODS}

In an explorative study of resource utilisation of the families of intellectually disabled children, 30 families attending a special school for intellectual disability were randomly chosen. The longitudinal history of attempts at care of the child through various alternate methods, their socio-demographic details, their perception of the problem, experiences with various systems of management and the resource utilisations were studied by a semi-structured questionnaire, which was formulated after doing a pilot study on 10 caregivers.

\section{RESULTS}

It was made out that most of the caregivers spent beyond their resources to somehow bring about an improvement. Moreover, they were wary of the possible adverse effects of drugs in allopathy and were disappointed by the lack of quick improvement. Advice by well-meaning relatives and trial for the sake of trying were other reasons.

\section{DISCUSSION}

Early diagnosis, proper guidance, care rather than cure, communicating the limitations of treatment and emphasis on possible rehabilitation methods, coordination among the various health care providers were identified as better remedial measures.

\section{KEYWORDS}

Intellectual Disability, Alternate Systems of Medicine, Family Resources.

HOW TO CITE THIS ARTICLE: Kanesalingavelan K, Sabhesan S, Nammalvar N, et al. Alternate approaches to intellectual disability. J. Evolution Med. Dent. Sci. 2016;5(75):5539-5541, DOI: 10.14260/jemds/2016/1251

\section{INTRODUCTION}

Intellectual disability is a disorder with onset during the developmental period that includes both intellectual and adaptive functioning deficits in conceptual, social and practical domains. The diagnostic term intellectual disability is the equivalent term for the ICD-11 diagnosis of intellectual disability disorder. Moreover, the term replaces the older familiar term mental retardation (Public Law United States 111-256, Rosa's Law).[1].

In any illness, awareness initiates the therapeutic process and attitude sustains it. Both awareness and attitude depend upon many factors such as the caretaker's knowledge, his potential to search, the environmental inputs, and the feedback during the therapeutic process. Anxiety and vacillations obtund the motivational levels, particularly when definitive therapies are not well established, improperly

Financial or Other, Competing Interest: None.

Submission 10-08-2016, Peer Review 01-09-2016,

Acceptance 09-09-2016, Published 16-09-2016.

Corresponding Author:

Dr. Kasinadar Kanesalingavelan,

3, Sonaiyar Koil Street,

Narimedu, Madurai-625002,

Tamilnadu.

E-mail: kanesandr@gmail.com

DOI: $10.14260 /$ jemds $/ 2016 / 1251$ practised or desperately disputed between the systems

(Gandotra, 1984; Jackson, 2002).[2,3].

Intellectual disability, particularly in those with physical handicaps and/or behaviour problems poses a challenge both to the parents and to the physician (Sen and Tuli 1991) ${ }^{[4]}$ Except in a few, aetiological diagnosis cannot be established and management ranges from special educational approaches to custodial care. Centres catering to clinical management are few and methods of habilitation are decided more by environmental determinants than by scientific validation. Anxiety about the child's future and false hopes make the parents shift focus to various alternate methods, including magico-religious approaches. Belied hopes based on inflated expectations do more harm to the motivation of the parent and to his purse (Rastogi, 1981; Chaturvedi and Malhotra, 1984).[5,6] Lack of realistic appraisal, defined goals and clearcut approaches end up in patient-mismanagement and parental despair (Kashyap, 1991).[7]

\section{AIMS AND OBJECTIVES}

The present study aims to understand the prevailing alternate approaches to the management of the intellectual disability and to evaluate how proper matching of the problem and the solution could be done in native context. 


\section{MATERIALS AND METHODS}

The study was conducted in Maria Montessori School for the Intellectual Disability during January - March 2016. Data was collected on a naturalistic research design. The clinical psychologist (M.N.) screened the patients prior to admission into the school either as an inmate or as a day student.

Parents and their intellectually disabled children were chosen consecutively on the basis of the following criteria:

1. Mental sub-normality of any severity was taken up, if it was diagnosed so by the psychologist during the screening.

2. Only patients with mental intellectual disability from birth were chosen.

3. Patients who had developed intellectual disability after a period of normal growth such as those due to encephalitis or meningitis were excluded.

4. Parents should be willing and cooperative.

Parents were interviewed using a semi-structured questionnaire. The questionnaire was formulated on the basis of clinical experience of the senior authors and a pilot study was conducted on ten parents. Based on the responses and difficulties, the questionnaire was modified and its final version arrived at. This questionnaire included sociodemographic details of the parents, their perceptions about the problem, various systems of management that they had taken recourse to, their expectations, their experiences with each system and the economic aspects of management under each approach.

After explanation of the study aim, parents were asked to give their written consent to participate in the study. The study received the approval from the Ethics Committee of the School.

As the design was naturalistic, enumerative statistics were used predominantly in analysis of the data.

\section{RESULTS}

The study shows that the children were in the school-going age group, they belonged to a predominant middle socioeconomic group and that the parents were at least minimally educated. Most of them had behaviour problems and one in five had seizure disorders. Severe and profound degrees of intellectual disability were prominently absent. Majority were dependent to the extent that they needed frequent help in their day-to day life. One in five evinced full dependence on the staff for daily living.

All the parents had consulted at least some doctors, including specialists before digressing into other systems of approach. The specialists included paediatricians, neurologists, orthopaedic consultants, physiotherapists, ENT consultants, speech therapists and ophthalmologists, mostly on referral from their physician and for specific complaints. They had also consulted other systems, such as Siddha, Ayurveda and Homeopathy and had resorted to magicoreligious approaches frequently. Siddha approach had been costlier than other systems, Homeopathy was the least and allopathy being somewhere in between. Expenditure on religious rituals had been considerable.

Reasons for consultation varied, but no patient cited financial reasons or non-availability of doctors as reasons for approaching other systems. The major cause was due to the opinion that allopathy is not safe and that other systems were trouble-free. Adverse effects such as drowsiness were cited as reasons by one tenth of the parents. Lack of improvement was cited as a reason by an equal number and one in four wanted to try other systems for possible better results.

\begin{tabular}{|l|c|c|}
\hline & Number & $\mathbf{\%}$ \\
\hline Age: Below 5 years & 0 & 0 \\
5 to 10 years & 12 & 40 \\
Above 10 years & 18 & 60 \\
\hline Sex: Boys & 9 & 30 \\
Girls & 21 & 70 \\
\hline Domicile: Rural & 12 & 40 \\
Urban & 18 & 60 \\
\hline Economic Status: Upper & 2 & 6.7 \\
Middle & 24 & 80 \\
Lower & 4 & 13.4 \\
\hline Education of caretaker: & 2 & \\
Illiterate & 12 & 6.7 \\
Below 5 years & 12 & 40 \\
5 to 10 years & 4 & 13.4 \\
More than 10 years & \multicolumn{2}{|c|}{ Table 1: Sociodemographic Variables of the Cohorts } \\
\hline \multicolumn{2}{|c|}{}
\end{tabular}

Total number of children: 30

\begin{tabular}{|l|c|l|}
\hline & Number & $\%$ \\
\hline Severity of Retardation: & 10 & 33.3 \\
Mild (Educable) & 20 & 66.7 \\
Moderate (Trainable) & 0 & 0 \\
Severe (Custodial) & 0 & 0 \\
Profound (Custodial) & 6 & 20 \\
\hline Seizure Disorder: & 24 & 80 \\
Present & 30 & 100 \\
Absent & 0 & 0 \\
\hline Behaviour problems: & 5 & 17 \\
Present & 19 & 53 \\
Absent & 6 & 20 \\
\hline Dependence: & & \\
Minimal & Frequent help & \\
Totally dependent & \multicolumn{2}{|c|}{ Table 2: Clinical Variables of Intellectual Disability } \\
\hline \multicolumn{2}{|c|}{} \\
\hline
\end{tabular}

Total number of children: 30

\begin{tabular}{|c|c|c|c|c|}
\hline Systems & $\begin{array}{c}\text { No. of } \\
\text { Children }\end{array}$ & $\mathbf{\%}$ & $\begin{array}{c}\text { Duration } \\
\text { (In } \\
\text { months) }\end{array}$ & $\begin{array}{c}\text { Expenses } \\
\text { (Per } \\
\text { Month) }\end{array}$ \\
\hline Ayurveda & 5 & 17 & $2-5$ & $600-1100$ \\
\hline Siddha & 12 & 40 & $5-12$ & $750-1300$ \\
\hline Homeopathy & 10 & 33 & $2-4$ & $100-400$ \\
\hline Religious & 20 & 67 & $3-24$ & $200-500$ \\
\hline
\end{tabular}

Table 3: Alternate Approaches sought by Parents

Total number of respondents: 30 .

Total exceeds 30 , as some families had tried more than one method.

\begin{tabular}{|c|c|c|}
\hline Reasons for Consultation & Number & $\mathbf{\%}$ \\
\hline Advised by others & 6 & 20 \\
\hline Feels that other systems are safe & 15 & 50 \\
\hline Lack of improvement & 18 & 60 \\
\hline Adverse effects of drugs & 3 & 10 \\
\hline Feels that it is a divine curse & 0 & 0 \\
\hline Just to try & 6 & 20 \\
\hline Financial & 0 & 0 \\
\hline Facility not reachable & 0 & 0 \\
\hline Table 4: Reasons for Consultation of other Systems \\
\hline
\end{tabular}


Total number of cohorts: 30 .

Total number exceeds 30 because of more than one reason given by some parents.

\section{DISCUSSION}

Results indicate that despite financial constraints, parents were anxious to get the children treated properly (Sen and Tuli, 1991) ${ }_{[3]}$. The parents in the study would strain to spend a few hundreds per month for special school and would consider spending some more in any other system, if that could benefit the children. They would not even consider reducing the amount spent on religious rituals. The financial strain and the switching over to different systems indicate that their anxiety has not been addressed to properly. Responses from the parents indicated that none of the practitioners, including the specialists had discussed with them in detail the limitations of the treatment and the need for special education methods in managing them. Often, continued prescriptions of vitamins, tonics and nootropics have given them a false hope. Despair and anxiety have naturally followed. Certain practitioners of alternate approaches have even promised them 'total cure' and 'complete return to normal' following treatment.

WHO (1987) [8] defined Health Systems Research as the systematic study of the means by which biomedical and other relevant knowledge was brought to bear on the health of individuals and communities under a given set of conditions. Throughout the native context, there was a major schism between the professional health culture of the elite and the lay health culture, which influenced the majority. Moreover, majority of the native practitioners and those in the indigenous systems have adapted to a 'syncretic' health culture. Such an arrangement confuses the anxious parents about the choice of their approach. Native belief that indigenous systems are nature-oriented and safe and that allopathic system is synthetic and wrought with side effects was deeply ingrained in their psyche. Half of the parents felt that indigenous systems were safer and could be tried. Moreover, most of the parents felt that simultaneous management along more than one approach was not inimical and could even be summative (Mak, 2002) [9].

Choice of the systems was an indicator of the prevalent modes of approach. Unani, Ayurveda, Naturopathy and special diet approaches have not been popular in the region and none of the respondents have ever heard about them. Siddha and Homeopathy have been prevalent and their use of the 'English medicines' has been noteworthy. Similarly, among the allopathic practitioners also, prolonged use of vitamins, nootropics and tonics (sometimes, for years) was observed.

\section{LIMITATIONS OF THE STUDY}

The study had involved children in a private special education school and from financially stable families. The number of children who could be approached was expectedly small. An elaborate community survey involving children from all socio-economic strata would be more informative. Moreover, more severely retarded children with severe degrees of physical and behavioural handicaps should be included to enable understanding of the society's coping with the untrainable children (Isaac, 1992). [10]

\section{CONCLUSION}

Native health-beliefs, hearsay, frustration with lack of expected improvement and anxiety to somehow do 'something' were the major reasons for consultations with other approaches. Most of them have failed to share their anxieties with their physician and take their guidance. Realistic appraisal of the problem, scientific evaluation of the outcome and clear-cut directions regarding whom to approach for what should be guiding principles of the management. Ideal person may be a paediatrician or any other health care provider with a special interest and dedication in this area and who could integrate all the treatment modalities with special education. Early coordination with a psychiatrist and a psychologist could add up to his validated judgments and could avoid much of the parental anxiety and unwanted detours in management. An early and able medical counselling and a holistic approach would avoid much of the psychological and financial maladies for these helpless parents and the intellectually disabled children.

\section{REFERENCES}

1. Desk reference to the diagnostic criteria from DSM-5. American psychiatric association, CBS Publishers and Distributors Pvt. Ltd., 2013.

2. Gandotra VS. Management problems and practices of home-makers with a disabled member in the family. Indian Journal of Social Work 1984;45:485-90.

3. Jackson M. Mental retardation. In: Freeman H. Edr. A century of psychiatry. New Delhi: Mosby 2002:237-40.

4. Sen A, Tuli K. Agonies of the family having a mentally handicapped child. In: Unit for family studies. eds. Research on families with problems in India. Vol. II. Bombay: Tata Institute of Social Sciences 1991:299-312.

5. Rastogi CK. Attitude of parents towards their mentally retarded children. Indian Journal of Psychiatry 1981;23(3):206-9.

6. Chaturvedi SK, Malhotra SA. A follow up study of mental retardation focusing on parental attitudes. Indian Journal of Psychiatry 1984;26(4):370-6.

7. Kashyap L. Research on families with disabled individuals: Review and implications. In: Unit for family studies. eds. Research on families with problems in India. Vol. II. Bombay: Tata Institute of Social Sciences 1991:269-89.

8. World Health Organization Health Behaviour Research. New Delhi: WHO,1987.

9. Mak FL. Traditional medicine and cultural factors in Asia. In: Freeman H. edr. A century of psychiatry. New Delhi: Mosby 2002:211-13.

10. Isaac MK. Role of paraprofessionals and nonprofessionals in mental health care in India. In: Murthy SR, Burns BJ. eds. Proceedings of the Indo-US symposium on community mental health. Bangalore: NIMHANS 1992;171-90. 